\title{
REPENSAR LA MÚSICA I LA LITERATURA DE BASE POPULAR \\ AMB UN ENFOCAMENT PEDAGÒGIC \\ Vicent Vidal \\ Universitat d'Alacant
}

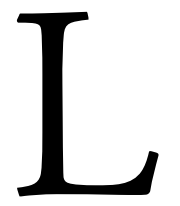

a música i la literatura formen part dels currículums acadèmics des de ben antic. Les set arts liberals que s'ensenyaven en les universitats medievals es dividien en el trivium (les disciplines literàries: gramàtica, dialèctica i retòrica) i el quadrivium (les disciplines científiques: l'aritmètica, la geometria, l'astronomia i la música). Amb aquestes disciplines hom s'assegurava una formació intel.lectual general. I, qui no pogués accedir a una formació reglada, era educat per mitjà del folklore - això inclou la música popular-, que ha servit com a eina pedagògica especialment, però no exclusivament, en les societats no alfabetitzades.

La música i la pedagogia han estat camps de recerca fructífers i llargament debatuts; semblantment, la nostra literatura de base popular ha estat analitzada des d'una perspectiva pedagògica, com a mínim, des de mitjans del segle passat, i amb un interés creixent. Tanmateix, són menys freqüents les ocasions acadèmiques en què les tres disciplines convergeixen i s'aplega un marc idoni pe $r$ estudiar-les conjuntament $i$ des de diverses perspectives. Aquesta ha estat la idea en la proposta de dedicar el vuité monogràfic de la revista a «música, pedagogia i literatura de base popular».

Així, les diverses contribucions al monogràfic han generat un volum crític que permet dilucidar algun dels interrogants que ens podem plantejar quan es tracten aquests temes. Per exemple, quin ha estat el recorregut de la música infantil i juvenil valenciana? Quines possibilitats didàctiques ofereix la música en valencià? Com és la intersecció que es produeix entre la nostra música d'autor i la música popular? Com són les lletres que en resulten? Quines metodologies d'ensenyament musical han existit a casa nostra? Quines manifestacions populars han marcat una època? Com es pot aprofitar tot plegat en l'ensenyament?

Les maneres d'aproximar-s'hi i d'intentar possibles respostes són diverses: estudis escrits amb perspectiva cronològica que fan un repàs per les 
aportacions essencials en cada camp; estudis de tipus més monogràfic centrats en la trajectòria o les circumstàncies d'un autor, una obra o uns fets; propostes didàctiques concretes adreçades a la millora de la pràctica educativa actual; i, en la majoria dels casos, reflexions interdisciplinàries en què música, pedagogia i literatura són les peces centrals.

Tots els estudis inclosos en aquest número treballen aquests aspectes d'una manera o altra, però s'hi poden diferenciar dos grans blocs segons el focus o el punt de partida. En el primer bloc, els tres primers articles contenen clarament un element de base popularitzant - en comparació, o no, amb la reelaboració culta - que vertebra un conjunt d'actes i fets que cal estudiar contextualment: la cançó «Tio Canya» d'Al Tall, dos costums del cicle de Pasqua i la música popular i actual a l'escola; en el segon bloc, format pels tres articles restants, el focus és eminentment musical: sobre metodologia, sobre música infantil i sobre el grup Obrint Pas. Caldria, però, precisar-ne millor els objectius i continguts.

Encapçala el monogràfic l'article «Obrim noves portes amb les claus del Tio Canya: la creació de la identitat. L'exemple d'una cançó i algunes possibles aplicacions», de la professora Francesca Cano (IES Rodolfo Llopis, Callosa d'en Sarrià). En aquest paper es planteja un recorregut al llarg i a l'ample de la transcendència històrica, social i educativa de la coneguda cançó d'Al Tall, «Tio Canya»: tot un símbol de la identitat col-lectiva dels valencians i una síntesi poètica del procés de substitució i de normalització lingüística al País Valencià. Amb aquest punt de partida, Cano explora les possibilitats didàctiques de la cançó i n'analitza intertextualitats i referències en la cultura contemporània i en la música d'autor. En un context globalitzat i desarrelat, les reflexions a l'entorn del «Tio Canya» i la difusió dels productes culturals existents poden illluminar el camí per estimular el retrobament amb la identitat dels valencians.

El retrobament - la descripció, l'anàlisi- dels costums del passat ha estat una preocupació constant, de fet, des que la societat experimenta uns canvis socials accelerats i pregons arran de la industrialització, la globalització i l'aparició de les tecnologies de la informació i la comunicació. Les maneres de viure i de relacionar-se han passat a ser ben diferents amb els temps. En aquest sentit, l'article «Ritus i costums del cicle de Pasqua», de M. Del Mar Reus Bas (Ajuntament de Dénia) estudia dos costums del 
cicle de Pasqua de la localitat de Xàbia que actualment han desaparegut: la salpassa, que anunciava l'inici de la Setmana Santa, i la colla dels «gloriosos», uns versadors particulars que, durant el Dissabte de Glòria, anunciaven la seua visió dels problemes de la localitat. Els dos costums, de to lúdic, crític o satíric, enllacen amb la tradició jocosa del cicle pasqual a casa nostra i mostren de quina manera la cultura popular, fent ús de la seua literatura, és capaç d'incidir sobre la realitat immediata.

Amb la voluntat de proposar un trasllat del folklore a l'educació, Carles Millà, graduat en Mestre en Educació Primària per la Universitat d'Alacant, defensa, en «Literatura popular en Educació Primària: de la tradició folklòrica a les noves tendències de música actual», que els docents integren la cançó popular i la música actual en valencià com a part del procés d'ensenyament-aprenentatge en l'educació primària. Entre les diverses idees, Millà destaca la cançó popular com a objecte d'interés per als nivells inicials, mentre que considera la música valenciana actual com una eina més adequada per ser utilitzada en els nivells superiors. Són múltiples els grups i els recursos musicals que, amb una selecció $i$ un tractament adients per part del professorat, poden arribar a l'aula transversalment a fi de fomentar l'esperit crític, l'educació en valors i el treball de les habilitats comunicatives. L'autor, en definitiva, adverteix de la necessitat de crear una «cultura musical valenciana» en l'alumnat, en la línia d'altres autors del monogràfic, com una manera per arribar a consolidar una identitat pròpia, definida i significativa per als valencians.

En «L'ensenyament musical de mossén Vicent Garcia Julbe», de Francesc Rocamora Riquelme (IES Federica Montseny, Badia del Vallès) s'obre un conjunt de tres articles més centrats en els aspectes musicals que no en els popularitzants. Si fins ara s'havia parlat dels referents musicals com a «creadors», en aquest cas Rocamora aprofundeix en l'obra d'un referent musical com a pedagog: mossén Vicent Garcia Julbe fou Canonge Prefecte de Música Sagrada de la Catedral de Tortosa des de 1949 i esdevingué director de la Schola Cantorum i professor de cant gregorià, de piano i de composició al Seminari Diocesà. Rocamora repassa diversos mètodes d'ensenyament musical del segle XX i situa, així, l'extraordinària tasca musical del capellà al seminari, entre l'ensenyament tradicional i la innovació: tingué l'encert d'incorporar estratègies gens habituals en l'època. Tot 
plegat esdevingué decisiu per a la formació d'una fornada de músics de reconegut prestigi.

Sense deixar la música i l'ensenyament, cal ressenyar l'article «La cançó tradicional infantil: el fenomen Dani Miquel, alguns precedents i coetanis», de Francesca Cano, autora que, per l'interés i la pertinència de l'objecte d'estudi, ha merescut una doble aparició en aquest monogràfic. En aquest cas, Cano examina el rumb de la música infantil valenciana des dels anys 70 ençà en una panoràmica que abraça els principals grups i cantants que han passat per l'escena valenciana i que han representat un paper fonamental en l'ensenyament. Grups i cantautors com Al Tall, Paco Muñoz, Carraixet, projectes com els Tallers de Música Popular, Musiescola, Com sona l'ESO, Projecte Oliveta o la base de dades Canpop són només alguns dels noms que sonen quan es mira enrere - $\mathrm{i}$ al costat - d'un projecte tan sòlid i d'un èxit tal com el de Dani Miquel. L'autodenominat «cantacançons» - compost paral.lel al de «contacontes»- ha suposat una veritable pedra de toc dins del context musical valencià infantil. La igualtat, l'educació en valors o l'estima per la llengua, però, són temes que traspassen les cançons de Dani Miquel i sobrevolen, en general, la música infantil en valencià, fet que regala a l'escola un producte atractiu, genuí, útil i necessari per al desenvolupament dels infants.

Per últim, l'article que tanca el monogràfic, «Obrint Pas: de la Nova Cançó al fenomen actual de la música en valencià», de Roser Durà (Màster en Comunicació i Mediació Cultural, Universitat d'Alacant), analitza la trajectòria i la significació del grup Obrint Pas, un punt d'inflexió en la música valenciana recent, un referent per a tota una generació de joves. Baula entre la Nova Cançó i els grups musicals més recents, el fenomen Obrint $\mathrm{Pas}$ marcà els anys noranta amb un estil propi, arrelat en la música popular valenciana i tombant fronteres per a la música en valencià: dels territoris de parla catalana, primer, a gires arreu d'Espanya, després, fins a països de tota Europa, Amèrica i Àsia. En una segona part, l'autora es deté a contrastar les formes poètiques de la Nova Cançó amb les lletres d'Obrint Pas, remarcant coincidències força interessants respecte a l'ús de recursos retòrics i formals provinents, en última instància, de la música de tradició oral; i de situacions parallleles tal com es revela amb l'ús de camps semàntics clau com «terra», «lluita», «guerra»o «emocions». 
Comptat i debatut, considerem que la formació de les generacions que pugen ha de passar, necessàriament, per la creació d'individus lliures que siguen capaços d'explotar al màxim les seues capacitats intel.lectuals. La música i la literatura han format part de l'educació, reglada o no, des de ben enrere, com a eines bàsiques per a la formació de persones crítiques, responsables i conscients del propi entorn. Per això, no podíem desaprofitar l'ocasió de coordinar i prologar un conjunt d'estudis dedicats, essencialment, a reivindicar la necessitat acadèmica de repensar la música i la literatura de base popular perquè, ben associades amb la pedagogia, generen aportacions fecundes per construir una societat, precisament, més crítica, més responsable i més conscient. 